\title{
Book Review \\ Constructing Futures: Industry Leaders and Futures Thinking in Construction
}

Paul Chan and Rachel Cooper, Wiley-Blackwell 2011, 224 pages, ISBN: 9781405157971 (hardback), GBP 69.99, AUD 140.00

"The fact that I wear red trousers, it's not a political or artistic take." Thus says George Ferguson, RIBA ex-president, one of the fifteen influential people in UK construction who have been interviewed by Chan and Cooper. Fourteen men and one woman, Sandi Rhys Jones. They talk freely about construction, and what they say has been gathered under the headings of two main chapters: 'sustainability' and 'connecting stakeholders', mixed with the views of the authors. After a while, the reader discovers that the true focus of this book is the social dimension.

This is preceded by a review of ten studies of the future of construction, published over the last two decades. Analytical future studies relying on formalized methods of forecasting received a blow by the 1973 oil crisis and its consequences for the stability of the world economy. Thus extrapolating the present lost much of its attraction. When John Major replaced Margaret Thatcher in 1990, there was soon a revival of industrial and innovation policies together with a wave of future or foresight studies, which were or are more like industry consensus exercises than unbiased, scientific analyses of trends. The semiscientific Delphi method, based on independent and anonymous expert guesses, merged with old-style commissions of the great and the good to create the foresight style of cosy discussion of industry problems.

Chan and Cooper have looked at three such UK construction foresight reports, three US future studies, one Swedish (clearly UK inspired) vision and finally the Australian Construction 2020 exercise. As with foresight studies for other industries, if you have read one of them, you have read all. So here they are, the drivers for change, extracted and sorted by our authors: ageing population, climate change, individualism, lifestyle expectations, political change, rise of China/India (does anybody remember the threat from the big Japanese contractors in the 1980s?), technology and communication, as well as the 9/11 latecomer, terrorist threat.

What can be done to deal with what the authors see as current problems in the industry? Central government, with all its limitations, does appear as an important force for change. However, the reader who wishes to pursue the role of government will have to remain dependent on Change in the Construction Industry, the 2006 book by David Adamson and Tony Pollington, who chronicled and analysed the UK construction industry reform movement. It is surprising that this analysis has not been mentioned by Chan and Cooper, who otherwise have many useful references to literature hidden in their endnotes. Given that the fifteen interviewees are all from the UK construction industry, not few of the problems raised in the book are peculiar to British society and can be difficult for a foreign readership to recognize. Nevertheless, since the Latham and Egan reports were read avidly by 1990s policy makers in many countries, the present round of interviews is valuable.

Finally, three themes are identified: emergence, boundaries and contradictions; readers may perhaps wonder whether any type of 'industry change' can do without these three. The word 'emergent' often occurs. The future is described as elusive, nebulous, fluid, full of ambiguities and paradoxes. As if the present situation is crystal clear to us. 
While the authors disclaim scientific intentions, it is still heavy reading, and there are symptoms of an overexpanded vocabulary, which could have done with some editorial care to protect both the authors and the readers from curious uses of unusual words. However, Chan and Cooper have written a book that contains many interesting thoughts.

\author{
Jan Bröchner \\ Chalmers University of Technology \\ Göteborg, Sweden
}

